\title{
Embedded screen-printed transducers in bulk polymer microfluidic devices
}

\author{
M. A. Hintermüller, C. Offenzeller, M. Knoll, W. Hilber, B. Jakoby
}

\begin{abstract}
We present a low-cost method to fabricate microfluidic devices with embedded transducers suitable for rapid prototyping on a lab scale and potentially also for mass production. To achieve this goal, a method for fabricating passive microfluidic devices using a solvent bonding technique for sealing is introduced. To avoid clogging, liquid metal (gallium) is utilized as a sacrificial layer during this bonding process. A sensor fabrication method compatible with the rapid prototyping ambitions is screen printing. Sensors based on thermal, capacitive and mechanical effects are fabricated by screen printing and are embedded into channels. The proposed processing methods can be easily adapted to achieve specific requirements associated with different tasks in lab-on-a-chip devices.
\end{abstract}

Keywords: microfluidic channel fabrication; integrated sensors; flow velocity; permittivity

\section{Eingebettete siebgedruckte Transducer in polymerbasierten mikrofluidischen Systemen.}

In diesem Beitrag wird eine "Low-Cost"-Herstellungsmethode für mikrofluidische Chips mit integrierten Sensoren und Aktoren (Transducer) präsentiert. Aufgrund der Einfachheit des Prozesses ist er speziell für Rapid Prototyping in Forschungs- und Entwicklungslaboren geeignet, potentziell ist er jedoch auch für Massenproduktion anwendbar. Zunächst wird eine Herstellungsmethode für passive mikrofluidische Chips eingeführt, welche ein Lösungsmittelklebeverfahren anwendet, um die Chips zu versiegeln bzw. abzudichten. Um ein Verstopfen der mikrofluidischen Kanäle während dieses Klebevorgangs zu unterbinden, wird flüssiges Metall (Gallium), fungierend als Opferschicht während des Versiegelungsprozesses, in die Kanäle eingefültt. Als Herstellungsmethode für die integrierten Transducer wird Siebdruck gewählt, da dieser Prozess mit den Rapid-Prototyping-Ambitionen vereinbar ist. Siebgedruckte Sensoren basierend auf thermischen, kapazitiven und mechanischen Effekten werden in mikrofluidische Chips integriert und die gewonnenen Ergebnisse diskutiert. Die vorgestellten Fabrikationsmethoden können leicht auf verschiedenste Anforderungen angepasst und so auf spezifische Aufgaben in Lab-on-a-Chip-Systemen maßgeschneidert werden.

Schlüsselwörter: mikrofluidische Kanalherstellung; integrierte Sensoren; Strömungsgeschwindigkeit; Permittivität

Received January 28, 2020, accepted March 19, 2020, published online March 30, 2020

(C) The Author(s) 2020

\section{Introduction}

Traditional materials for microfluidic devices are commonly silicon or glass. Fabrication techniques for these materials are usually based on surface and bulk micromachining technologies [1-3]. With these fabrication processes, embedding of sensors and actuators for microfluidic tasks is also possible. Mass production of devices is feasible, but until a proper fabrication process is established, the development of suitable technologies is costly [4].

Over the last few decades, the use of polymeric microfluidic devices was established as a worthwhile alternative to these classic materials and technologies. Due to the wide variety of available polymer materials and processing techniques, combined with the usually affordable costs, they are especially suitable for rapid prototyping on a small scale, but also for mass production $[5,6]$. When using appropriate fabrication methods, transducers can be easily embedded into polymeric microfluidic devices. Screen printing technology is one of these suitable methods. Sensors and actuators produced by screen printing technique can be embedded into microchannels without disturbing the flow. Due to a wide variety of readily available screen printing inks, the process is highly flexible. As these inks are usually polymer based, compatibility with the base material can be ensured, resulting in proper adhesion of the printed features to the device.

In this work, we present a concept for integrating sensors and actuators into polymeric devices using a low-cost approach. First, a fabrication method for passive microfluidic devices using gallium as a sacrificial material during a solvent bonding process is presented. Based on this process, several examples for sensor integration, utilizing different physical effects, are discussed. Transduction elements presented here are based on thermal, capacitive and mechanical effects, for measuring quantities like flow velocity or relative permittivity of liquids inside microchannels. The proposed approach is highly flexible and can be easily adapted to other applications.

\section{Microchannel fabrication}

First, the fundamental fabrication process for passive, polymeric microfluidic devices is discussed [7]. A simple to use process is presented, which eliminates the need for special equipment for bonding (e.g. $\mathrm{O}_{2}$ plasma) by employing gallium as a sacrificial layer during

Hintermüller, Marcus A., Institute for Microelectronics and Microsensors, Johannes Kepler University Linz, Altenbergerstr. 69, 4040 Linz, Austria (E-mail: marcus.hintermueller@jku.at); Offenzeller, Christina, Institute for Microelectronics and Microsensors, Johannes Kepler University Linz, Altenbergerstr. 69 4040 Linz, Austria (E-mail: christina.offenzeller@jku.at); Knoll, Marcel, Institute for Microelectronics and Microsensors, Johannes Kepler University Linz, Altenbergerstr. 69, 4040 Linz, Austria (E-mail: marcel.knoll@jku.at); Hilber, Wolfgang, Institute for Microelectronics and Microsensors, Johannes Kepler University Linz, Altenbergerstr. 69 4040 Linz, Austria (E-mail: wolfgang.hilber@jku.at); Jakoby, Bernhard, Institute for Microelectronics and Microsensors, Johannes Kepler University Linz, Altenbergerstr. 69 4040 Linz, Austria (E-mail: bernhard.jakoby@jku.at) 

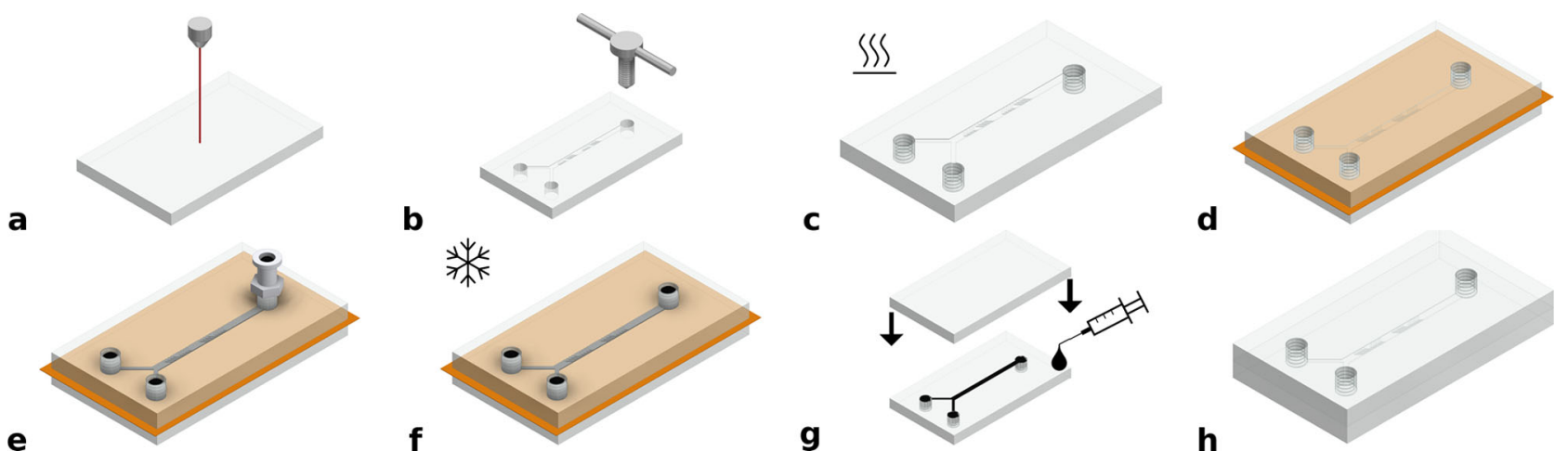

Fig. 1. General fabrication process: (a) Laser engraving the channel geometry. (b) Inlet and outlet thread cutting for easy connection via threaded Luer fittings. (c) Annealing for $1-2 \mathrm{~h}$ at $75^{\circ} \mathrm{C}$. (d) Temporary sealing by clamping together two PMMA parts with a thin polymer film in between. (e) Filling the channels with liquid gallium. (f) Freezing to solidify the gallium inside the channels at $-10^{\circ} \mathrm{C}$. (g) Applying solvent and pressing the parts together. (h) Flushing the gallium from the channels

a solvent bonding process. This makes the process especially suitable for rapid prototyping on a small academic lab scale.

The sequence of this fabrication process is shown in Fig. 1. First, the microfluidic channels are structured into a PMMA sheet using a laser engraver (Trotec Speedy 300 flexx, Fig. 1a). Note that also any other method for patterning the channels can be employed, e.g., micromilling or hot embossing. Mechanical threads are cut into the inlet and outlet ports, enabling easy and leakproof connection using threaded Luer adapters (Fig. 1b). As the laser engraving process causes rapid heating and rapid cooling of the polymer, thermal stresses are induced inside the material. If the engraved surface comes then in contact with a solvent, the stresses are relieved, leading to the formation of cracks around the engraved edges. This is commonly referred to as stress crazing $[8,9]$. In order to avoid this crack formation during the bonding process, performing an annealing step is recommended $[10,11]$. To this end, the engraved piece is placed in a box oven and heated up to approximately $75^{\circ} \mathrm{C}$, before allowing it to slowly return to room temperature (Fig. 1c). Next, the engraved piece is clamped channel side down to a glass slide, with a thin polymer film in between (Fig. 1d). This temporarily seals the channel, which makes it possible to fill in pre-heated liquid gallium (Fig. 1e). The workpiece is then cooled in a freezer at $-10^{\circ} \mathrm{C}$ for approximately 5-10 min, in order to solidify the gallium inside the channels (Fig. 1f). To eliminate the risk of supercooling the gallium, a small piece of solid gallium can be immersed in the liquid metal at one of the inlet or outlet ports. This piece of solid then acts as a seeding crystal, accelerating the process of solidification. Since the polymer film between the glass and the channel prevents the gallium from sticking to the glass, the glass slide can be removed subsequently, leaving the engraved channel filled with solid gallium. Next, a liquid solvent suitable to dissolve the channel material (here dichloromethane [12]) is applied to the top of a flat sheet of PMMA (the bottom plate). Against this surface the engraved workpiece is pressed, with the channel in direct contact with the solvent (Fig. 1g). The solid gallium prevents the channel from being clogged by dissolved polymer, which now seals together the two PMMA parts. Subsequently, the chip is submerged in warm water to liquefy the gallium again, which is then flushed from the channels using a weak sodium hydroxide $(\mathrm{NaOH})$ solution (Fig. 1h). Afterwards, the channels are cleaned using deionized water.

The described fabrication process can be employed to manufacture a variety of passive channel geometries performing different tasks in microfluidic devices, that, for example, can consist of intricate channel features, multiple branches, and three-dimensional structures inside the channel. Figure 2a shows a flow focusing device, which can generate monodisperse emulsions or foams. Deionized (DI) water colored with black ink and a small amount of dishwashing detergent flowed continuously from the vertical channels, whereas air flowed continuously from the horizontal channel. Due to an interplay of viscous forces and interfacial tension, monodisperse air bubbles are generated, where their size and frequency of generation depends on the capillary numbers (ratio of viscous forces to surface tension forces) and the size of the orifice [13]. Figure $2 b$ shows a chemical gradient generator. DI water mixed with blue and yellow ink, respectively, flowed from the inlets on the left side. The two colors were mixed via diffusion in the meander-shaped channels. After the third stage, five different concentrations were available. Creating such defined concentrations can be crucial for cell analysis [14]. The staggered herringbone mixer shown in Fig. 2c features asymmetrical grooves on the channel bottom to create vortices that improve mixing of the two liquids, compared to mixing by purely diffusion [15]. Here, DI water mixed with blue and red ink was mixed over the course of the four mixing stages. The minimum feature sizes of the devices shown here were in lateral direction $160 \mu \mathrm{m}$ (limited by the laser engraver spot size) and $80 \mu \mathrm{m}$ in vertical direction.

\section{Embedding of transducers}

In addition to being fast and low-cost, the beforementioned fabrication technique also allows for the embedding of sensors into microfluidic chips. Following the concept of rapid prototyping based on polymeric materials, screen printing is chosen as a manufacturing technique for processing polymer-based inks. In the following, several examples for screen printed sensors based on different physical effects are presented.

\subsection{Thermal effects}

One crucial parameter in lab-on-a-chip applications is the velocity of the flow inside microchannels. Widely used methods for monitoring this quantity are based on heat transfer, which can be generally divided into three categories. First, sensors that measure cooling due to the streaming fluid [16], second, sensors that measure an asymmetry of the temperature profile around a heater caused by the flow [17], and third, sensors that measure the propagation time of a heat pulse [18]. Thermal mass flow sensors can be operated in different 

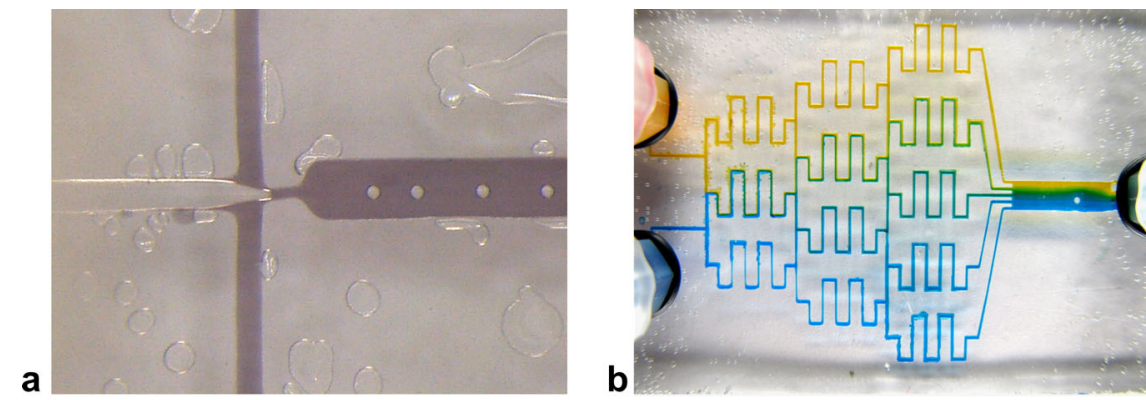

c

Fig. 2. Passive microfluidic devices: (a) Flow focusing device. (b) Chemical gradient generator. (c) Herringbone mixer (Color figure online)

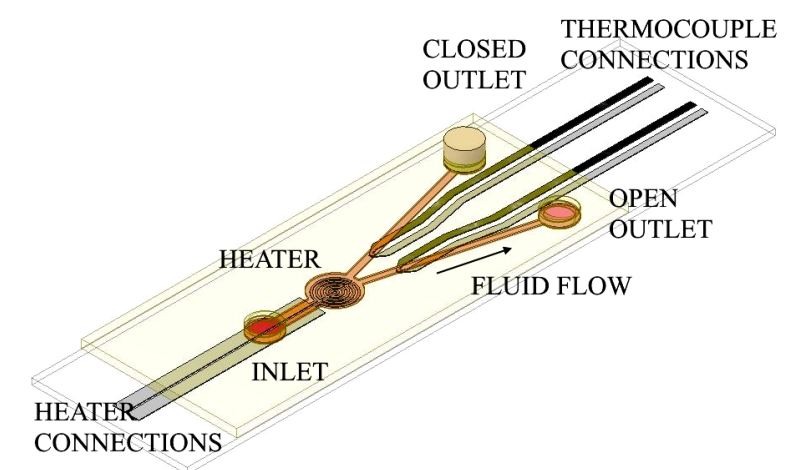

(a)

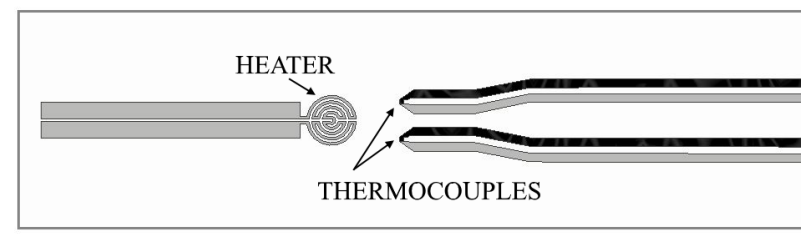

(b)

Fig. 3. Schematic of the thermal flow velocity sensor: (a) 3D view of channel setup (fluid in red). (b) Top view of sensor layout (Color figure online)

modes, keeping either the applied current (or voltage) constant, or the temperature of heating elements, which is achieved by a control circuit. Using the latter mode, the required power to keep the heating element on the same temperature is a measure for the flow velocity. Keeping the temperature constant eliminates thermal inertia of the sensor, yielding a higher limiting frequency as operation in constant current/voltage mode. Fast fluctuations in flow velocity can therefore be measured in this mode.

Here, we present a flow velocity sensor utilizing the convective heat transfer from a microheater to a temperature sensor [19, 20], which falls into the third category mentioned above. A schematic layout is shown in Fig. 3. The channel geometry consists of one circular chamber with two channels leading from it to two outlets. The sensor structure is designed in a way that a circular heater heats the fluid inside the chamber. A thermocouple is located in each down-

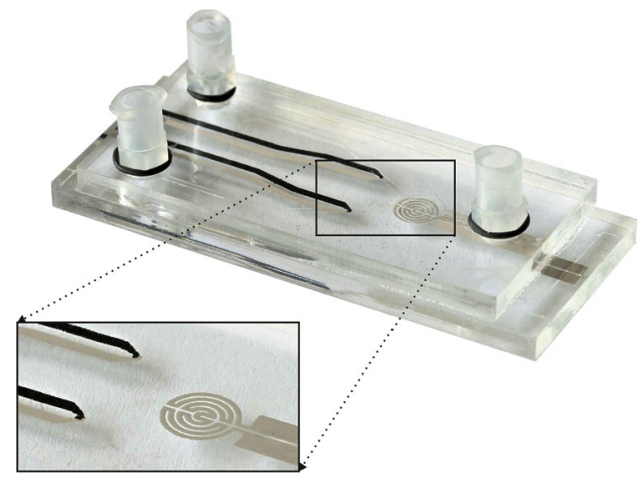

Fig. 4. Fabricated thermal flow velocity sensor. Grey and black lines are the screen printed silver and carbon black features

stream channel to record the temperature of the fluid in the respective channel. When the heater is turned on, heat is transported to the thermocouples via heat conduction and convection. One of the two channels is sealed so that no flow can take place. The temperature difference between the two channels is measured, which is approximately proportional to the flow velocity, as the conductive part of the heat transfer is equal in both channels. Therefore, a relation between the flow velocity and the temperature difference can be established.

The fabrication process of the device is the same as shown in Fig. 1a through 1f. Prior to the solvent bonding process, the described sensor layout is screen printed onto the bottom plate. To do so, first the silver features (heater and one half of each thermocouple) are printed from a polymeric screen printing ink with silver filler particles (KA801 by Dupont) using a 120 threads/cm PET mesh. After this print is dried at $100{ }^{\circ} \mathrm{C}$, the other halves of the thermocouples are printed from a carbon black filled polymer ink (EDAG PR 406B by Henkel) in two steps wet-in-wet using a 100 threads/cm PET mesh. Again, the printed structure is dried at $100^{\circ} \mathrm{C}$. To protect the printed structures during the solvent bonding process, a layer of PMMA (1:10 solution in anisole) is spin coated on top of it. The resulting PMMA layer thickness is approximately $10 \mu \mathrm{m}$. Following this sensor fabrication procedure, the channel fabrication process is resumed with step $1 \mathrm{~g}$ in Fig. 1. The fabricated microfluidic chip is 


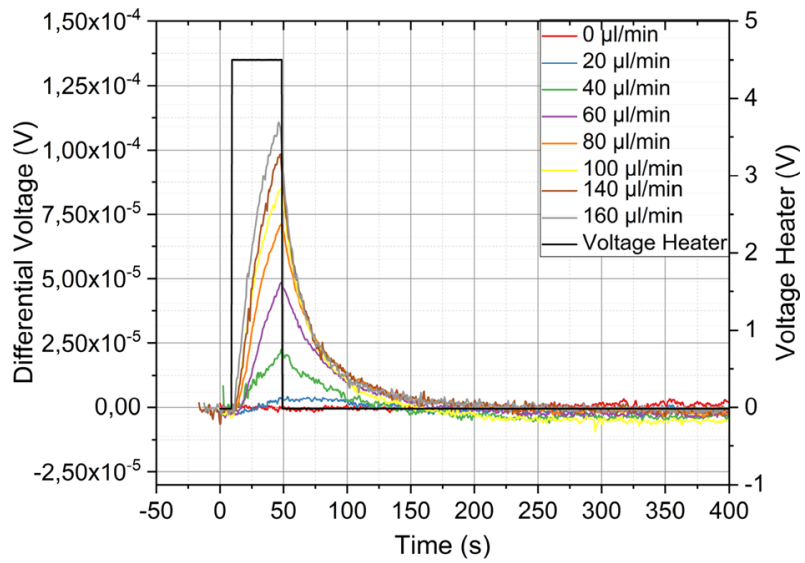

Fig. 5. Output signal of the thermal flow velocity sensor for flow velocities ranging from 0 to $160 \mu \mathrm{l} / \mathrm{min}$

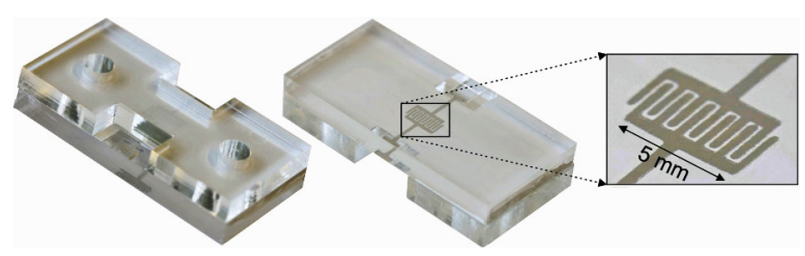

Fig. 6. Fabricated capacitive sensing element with $\mathrm{BaTiO}_{3} / \mathrm{PMMA}$ coating (white). Inset shows interdigitated electrode pair

shown in Fig. 4. The grey and black patterns seen in Fig. 4 are the screen printed silver and carbon black features, respectively.

Measurement results are shown in Fig. 5: The channel was filled with a test fluid (Titan OW30 oil by Fuchs) and flow was introduced by a syringe pump (ExiGo by Cellix). A power of $380 \mathrm{~mW}$ was applied to the heater for 40 seconds and the difference in temperature was recorded for a range of flow velocities (0 to $160 \mu \mathrm{l} / \mathrm{min}$ ). Measurements were performed at ambient temperature in the lab. As the thermal mass of the device is assumed to be relatively high, and the heating power relatively low, it is not expected that the device is warmed up significantly during a measurement. Additionally, enough time was given between measurements, to let the device return to ambient temperature. The reference point of the thermocouples was held constant using an aluminum block, whose temperature was controlled using a water bath to be $25^{\circ} \mathrm{C}$.

As seen in Fig. 5, the temperature difference increased with increasing flow velocity, which is in agreement with the assumption that this difference originates from the convective heat transfer. Note, that in a technical realization it would be beneficial to add temperature sensors on the device to monitor the ambient temperature, as this is crucial for the reliability of the measurements. Nevertheless, the underlying concept can be demonstrated without this addition.

\subsection{Capacitive effects}

Capacitive sensors can be used in a variety of applications in lab-ona-chip devices, e.g., material or droplet detection [21], monitoring of bacterial growth [22], the detection of viruses [23] and sensing of DNA [24] or chemical processes [25]. Suitable electrode configurations can also be processed by screen printing

A device for distinguishing fluids with different dielectric properties, which was fabricated using the aforementioned techniques, is shown in Fig. 6. An interdigitated electrode pair on the bottom plate

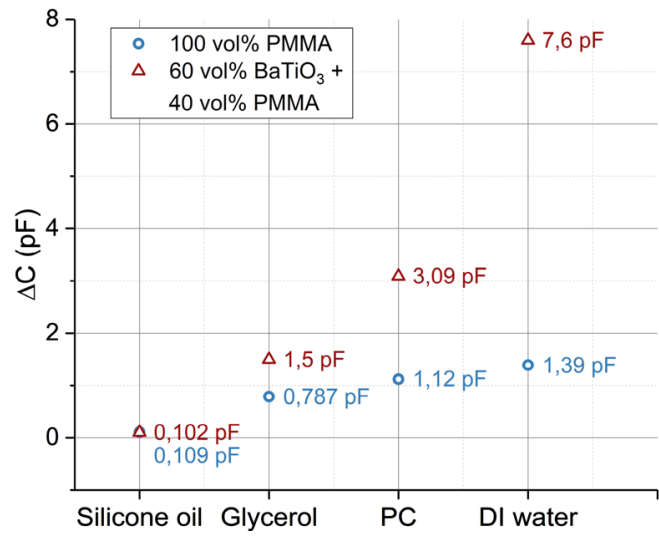

Fig. 7. Measurement results of capacitive sensing elements featuring insulating layers without (blue circles) and with (red triangles) $\mathrm{BaTiO}_{3}$. Relative permittivity of liquids: 2.7 (silicone oil), 46.5 (glycerol), 66 (propylene carbonate, PC), 80 (deionized (DI) water) (Color figure online)

forms a capacitor; the microchannel is placed directly above it. To avoid shorting of the electrodes via a conductive fluid, they are insulated by a thin polymer layer. Depending on the relative permittivity of the fluid inside the channel, the capacitance changes accordingly.

The fabrication process follows the same steps as mentioned above. The interdigitated electrode pair was screen printed (using the same conductive silver ink and screen printing mesh) on the bottom plate, before applying the insulation layer by spin coating process (again from a 10:1 anisole in PMMA solution). Measurement results showing the change in capacitance (compared to the air-filled microchannel) due to liquids with different relative permittivity are shown in Fig. 7 as blue circles.

The change in capacitance depending on the fluid inside the channel is given by

$$
\Delta C=\Delta \frac{C_{\text {fluid }}}{1+2 C_{\text {fluid }} / C_{\text {dielectric }}}
$$

with $C_{\text {fluid }}$ the capacitance related to the fluid inside the channel and $C_{\text {dielectric }}$ the capacitance associated with the dielectric layer [26]. An increase of the relative permittivity of the insulating layer leads to a higher $C_{\text {dielectric }}$ and therefore the total capacitance change depends stronger on the capacitance change caused by the fluid. Therefore, the sensitivity of the device can be increased by improving the dielectric properties of the insulating layer. One way to achieve this is by mixing in particles with a high permittivity, e.g., $\mathrm{BaTiO}_{3}\left(\epsilon_{\mathrm{r}, \mathrm{BaTiO}}\right.$ $\approx 500-6900$ [27]). To this end, the 10:1 anisole in PMMA solution was mixed with $\mathrm{BaTiO}_{3}$ particles. Subsequently, the mixture was milled in a planetary ball mill (for $8 \mathrm{~min}$ at $650 \mathrm{rpm}$ ) to achieve a homogeneous solution. A ratio of 40 vol\% PMMA to 60 vol\% $\mathrm{BaTiO}_{3}$ was found to have the highest relative permittivity [28]. The resulting dielectric coating was again applied by spin coating over the interdigitated electrodes. The permittivity of this dielectric was approximately 8 times higher than that of pure PMMA [28]. Therefore, as can be seen in the red triangles in Fig. 7, the sensitivity of the capacitive sensor increased significantly.

\subsection{Mechanical effects}

Besides thermal effects, also mechanical effects can be employed for measuring the flow velocity inside microchannels [29, 30]. According to Bernoulli's law, an increase in flow velocity leads to a reduced pressure in the channel. Here, a device is presented, which utilizes 


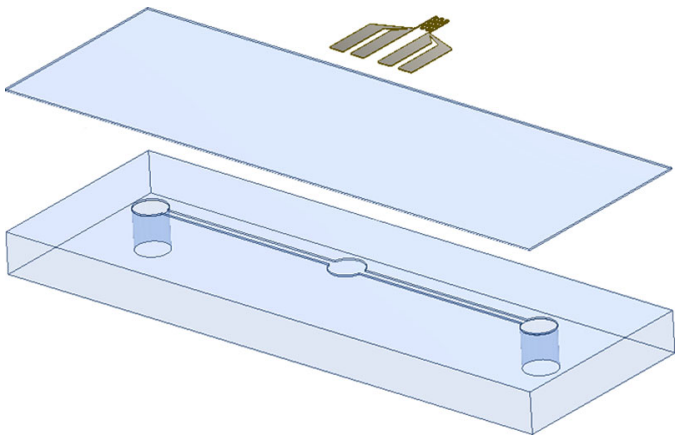

Fig. 8. Schematic of mechanical flow velocity sensor

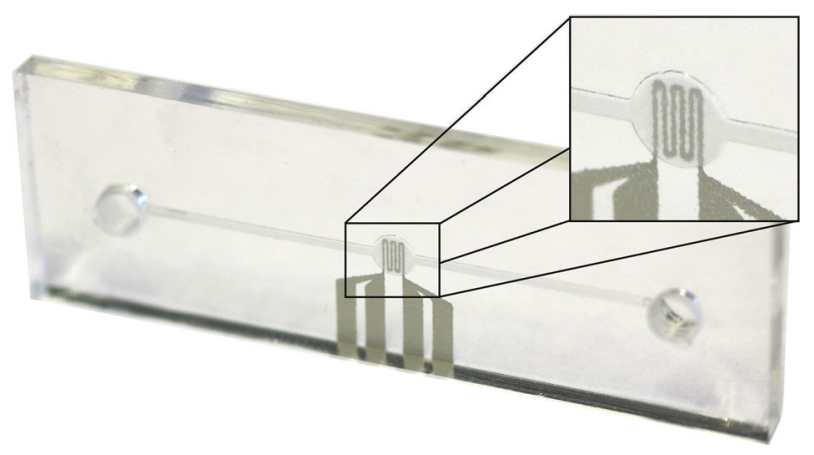

Fig. 9. Fabricated mechanical flow velocity sensor. Inset shows strain gauge on diaphragm

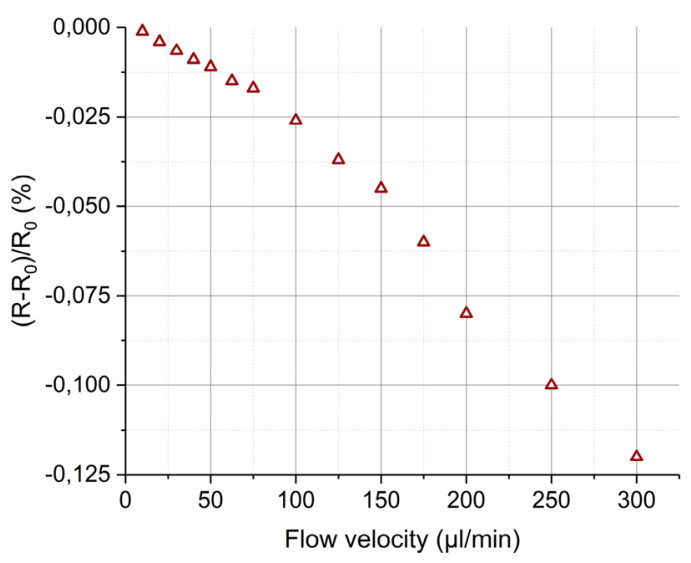

Fig. 10. Relative change of resistance of strain gauge as a function of flow velocity

a deformable diaphragm for measuring the flow velocity based on the aforementioned effect [31]. If the flow velocity increases, the reduced pressure causes the diaphragm to bend inwards. This deformation is monitored via a screen printed strain gauge on the surface of the diaphragm, which is located atop a circular chamber in the channel (see Fig. 8).

The fabrication process is again based on the process introduced in Sect. 2. However, in order to fabricate the diaphragm, the procedure is modified after step $f$ of Fig. 1. After removing the device from the freezer, a layer of UV curable PMMA is doctor-bladed on top of the gallium filled channel and subsequently crosslinked under UV irradiation for ten minutes. Next, the strain gauge is screen printed onto the surface of the cured PMMA layer in the area of the circular chamber. Here, the sensor is printed using a low temperature curing silver ink (C2121022D1 by Sun Chemical) in order to avoid the risk of damaging the thin UV-cured membrane. The sensor was printed using a 140 threads/cm PET mesh and cured at $75^{\circ} \mathrm{C}$ for $15 \mathrm{~min}$. The removal of the gallium was performed using the same method as in Sect. 2. The fabricated device is shown in Fig. 9.

Measurement results are shown in Fig. 10. The resistance of the strain gauge was measured using a digital multimeter in 4wire configuration. As can be seen, the relative change in resistance decreased with increasing flow velocity. Flow velocities above $300 \mu \mathrm{L} / \mathrm{min}$ cannot be distinguished anymore as the diaphragm is physically limited in deformation. Also, flow velocities below $10 \mu \mathrm{L}$ min cannot be detected due to the stiffness of the diaphragm. However, the design and thickness of the diaphragm can be adjusted in order to modify the measurement range.

\section{Conclusions}

In this work, a concept for integrating transducers into polymeric microfluidic devices was presented. Several possible application examples, based on different physical effects, were discussed. The proposed fabrication concept was found suitable for the low-cost integration of sensors and actuators into lab-on-a-chip applications. As demonstrated, the underlying concept can be easily adapted to meet the varying requirements of different applications in lab-on-achip devices. Due to this flexibility, it is especially suitable for rapid prototyping.

\section{Acknowledgements}

Open access funding provided by Johannes Kepler University Linz. This work has been supported by the COMET-K2 "Center for Symbiotic Mechatronics" of the Linz Center of Mechatronics (LCM) funded by the Austrian federal government and the federal state of Upper Austria.

Publisher's Note Springer Nature remains neutral with regard to jurisdictional claims in published maps and institutional affiliations.

Open Access Dieser Artikel wird unter der Creative Commons Namensnennung 4.0 International Lizenz veröffentlicht, welche die Nutzung, Vervielfältigung, Bearbeitung, Verbreitung und Wiedergabe in jeglichem Medium und Format erlaubt, sofern Sie den/die ursprünglichen Autor(en) und die Quelle ordnungsgemäß nennen, einen Link zur Creative Commons Lizenz beifügen und angeben, ob Änderungen vorgenommen wurden. Die in diesem Artikel enthaltenen Bilder und sonstiges Drittmaterial unterliegen ebenfalls der genannten Creative Commons Lizenz, sofern sich aus der Abbildungslegende nichts anderes ergibt. Sofern das betreffende Material nicht unter der genannten Creative Commons Lizenz steht und die betreffende Handlung nicht nach gesetzlichen Vorschriften erlaubt ist, ist für die oben aufgeführten Weiterverwendungen des Materials die Einwilligung des jeweiligen Rechteinhabers einzuholen. Weitere Details zur Lizenz entnehmen Sie bitte der Lizenzinformation auf http://creativecommons.org/licenses/by/4.0/deed.de.

\section{References}

1. Harrison, D. J., Manz, A., Fan, Z., et al. (1992): Capillary electrophoresis and sample injection systems integrated on a planar glass chip. Anal. Chem., 64, 1926-1932. https://doi.org/10.1021/ac00041a030.

2. Reyes, D. R., lossifidis, D., Auroux, P.-A., Manz, A. (2002): Micro total analysis systems. 1. Introduction, theory, and technology. Anal. Chem., 74, 2623-2636. https://doi. org/10.1021/ac0202435.

3. Terry, S. C., Jerman, J. H., Angell, J. B. (1979): A gas chromatographic air analyzer fabricated on a silicon wafer. IEEE Trans. Electron Devices, 26, 1880-1886. https://doi. org/10.1109/T-ED.1979.19791.

4. Ren, K., Zhou, J., Wu, H. (2013): Materials for microfluidic chip fabrication. Acc. Chem. Res., 46, 2396-2406. https://doi.org/10.1021/ar300314s.

5. Nge, P. N., Rogers, C. I., Woolley, A. T. (2013): Advances in microfluidic materials, functions, integration, and applications. Chem. Rev., 113, 2550-2583. https://doi.org/ $10.1021 / \mathrm{cr} 300337 x$. 
6. Tsao, C.-W., Microfluidics, P. (2016): Simple, low-cost fabrication process bridging academic lab research to commercialized production. Micromachines, 7, 225. https://doi. org/10.3390/mi7120225.

7. Hintermüller, M. A., Jakoby, B. (2019): Lab-scale prototyping of polymer based microfluidic devices using gallium as phase-changing sacrificial material. Microelectron Eng., 211, 50-54. https://doi.org/10.1016/j.mee.2019.03.025.

8. Jensen, M. F., Noerholm, M., Christensen, L. H., Geschke, O. (2003): Microstructure fabrication with a $\mathrm{CO}_{2}$ laser system: characterization and fabrication of cavities produced by raster scanning of the laser beam. Lab Chip, 3, 302. https://doi.org/10.1039/ b308153b.

9. Doran, D., Cather, B. (2013): Construction materials reference book. London: Routledge.

10. Klank, H., Kutter, J. P., Geschke, O. (2002): $\mathrm{CO}_{2}$-laser micromachining and back-end processing for rapid production of PMMA-based microfluidic systems. Lab Chip, 2 242. https://doi.org/10.1039/b206409j.

11. Hintermüller, M. A., Jakoby, B. (2019): Using gallium as a protective layer during a solvent bonding process for lab-scale polymer based microfluidic device fabrication In Proceedings of the 4th conference on microfluidic handling systems (MFHS 2019), Enschede (pp. 152-155).

12. Lin, C., Chao, C., Lan, C. (2007): Low azeotropic solvent for bonding of PMMA microfluidic devices. Sens. Actuators B, Chem., 121, 698-705. https://doi.org/10.1016/ j.snb.2006.04.086

13. Zhu, P., Wang, L. (2017): Passive and active droplet generation with microfluidics: a review. Lab Chip, 17, 34-75. https://doi.org/10.1039/C6LC01018K.

14. Wang, X., Liu, Z., Pang, Y. (2017): Concentration gradient generation methods based on microfluidic systems. RSC Adv., 7, 29966-29984. https://doi.org/10.1039/ C7RA04494A.

15. Stroock, A. D., Dertinger, S. K. W., Ajdari, A., et al. (2002): Chaotic mixer for microchannels. Science, 80(295), 647-651. https://doi.org/10.1126/science.1066238.

16. Neda, T., Nakamura, K., Takumi, T. (1996): A polysilicon flow sensor for gas flow meters. Sens. Actuators A, Phys., 54, 626-631. https://doi.org/10.1016/S09244247(97)80027-1.

17. Sabaté, N., Santander, J., Fonseca, L., et al. (2004): Multi-range silicon micromachined flow sensor. Sens. Actuators A, Phys., 110, 282-288. https://doi.org/10.1016/j.sna. 2003.10.068

18. Berthet, H., Jundt, J., Durivault, J., et al. (2011): Time-of-flight thermal flowrate sensor for lab-on-chip applications. Lab Chip, 11, 215-223. https://doi.org/10.1039/ COLC00229A.

\section{Authors}

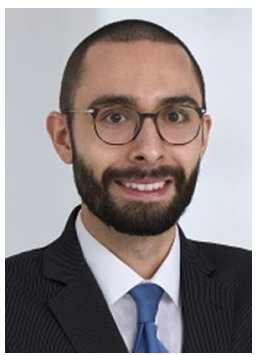

\section{Marcus A. Hintermüller}

was born in Linz, Austria, in 1990. He obtained his B.Sc. and Dipl.-Ing. (M.Sc.) degrees in Mechatronics Engeneering from the Johannes Kepler University Linz, Austria, in 2013 and 2016, respectively. Since then he holds a position as University Assistant at the Institute for Microelectronics and Microsensors at the Johannes Kepler University Linz, where he is working towards his doctoral (Ph.D.) degree. His current research focus is on the modelling and experimental investigation microfluidic effects and sensor integration in microfluidic devices.

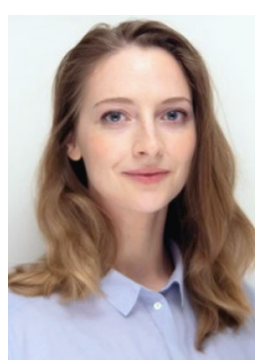

\section{Christina Offenzeller}

was born in Vöcklabruck, Austria, in 1992 She received the B.Sc. and Dipl.Ing. (M.Sc.) degrees in technical physics from Johannes Kepler University Linz, Austria, in 2014 and 2016, respectively. She is currently pursuing the Ph.D. degree with the Institute for Microelectronics and Microsensors, Johannes Kepler University Linz. Since 2017, she has been a Research Assistant at the Institute for Microelectronics and Microsensors, Johannes Kepler University Linz. The
19. Offenzeller, C., Hintermüller, M. A., Knoll, M., et al. (2019): Embedding of screen printed sensors and actuators inot bulk polymer for sensing in microfluidic devices. In Proceedings of the 4th conference on microfluidic handling systems (MFHS 2019), Enschede (pp. 97-100).

20. Offenzeller, C., Knoll, M., Voglhuber-Brunnmaier, T., et al. (2018): Fully screen printed thermocouple and microheater applied for time-of-flight sensing in microchannels. IEEE Sens. J., 18, 8685-8692. https://doi.org/10.1109/JSEN.2018.2868161.

21. Chen, J. Z., Darhuber, A. A., Troian, S. M., Wagner, S. (2004): Capacitive sensing of droplets for microfluidic devices based on thermocapillary actuation. Lab Chip, 4, 473. https://doi.org/10.1039/b315815b.

22. Ghafar-Zadeh, E., Sawan, M., Chodavarapu, V. P., Hosseini-Nia, T. (2010): Bacteria growth monitoring through a differential CMOS capacitive sensor. IEEE Trans. Biomed. Circuits Syst., 4, 232-238. https://doi.org/10.1109/TBCAS.2010.2048430.

23. Balasubramanian, A., Bhuva, B., Mernaugh, R., Haselton, F. (2005): Si-based sensor for virus detection. IEEE Sens. J., 5, 340-344. https://doi.org/10.1109/JSEN.2005. 844543.

24. Stagni, C., Guiducci, C., Benini, L., et al. (2006): CMOS DNA sensor array with integrated a/d conversion based on label-free capacitance measurement. IEEE J. SolidState Circuits, 41, 2956-2964. https://doi.org/10.1109/JSSC.2006.884867.

25. Hierlernann, A. (2005): Integrated chemical microsensor systems in CMOS-technology. In The 13th international conference on solid-state sensors, actuators and microsystems. Digest of technical papers. TRANSDUCERS '05 (pp. 1134-1137). New York: IEEE Press.

26. Elbuken, C., Glawdel, T., Chan, D., Ren, C. L. (2011): Detection of microdroplet size and speed using capacitive sensors. Sens. Actuators A, Phys., 171, 55-62. https://doi. org/10.1016/j.sna.2011.07.007

27. Vijatovic, M. M., Bobic, J. D., Stojanovic, B. D. (2008): History and challenges of barium titanate: Part I. Sci. Sinter., 40, 155-165. https://doi.org/10.2298/S0S0802155V.

28. Offenzeller, C., Hintermüller, M. A., Hilber, W., Jakoby, B. (2020): A dielectric coating for improved performance of capacitive sensors in all-polymer microfluidic devices. Microelectron. Eng., 223, 111220. https://doi.org/10.1016/j.mee.2020.111220.

29. Nguyen, N. (1997): Micromachined flow sensors-a review. Flow Meas. Instrum., 8, 7-16. https://doi.org/10.1016/50955-5986(97)00019-8

30. Wang, Y-H., Lee, C-Y., Chiang, C-M. (2007): A MEMS-based Air Flow Sensor with a Free-standing Micro-cantilever Structure. Sensors, 7, 2389-2401. https://doi.org/10. 3390/s7102389.

31. Knoll, M., Hintermüller, M. A. Offenzeller, C, et al. (2019): Additive manufactured pure PMMA microfluidic channels featuring a screen printed diaphragm flow velocity sensor. In Proceedings of the 4th conference on MicroFluidic handling systems (MFHS 2019), Enschede (pp. 89-92).

focus of her research is the embedding of printed electronics and sensors into surfaces

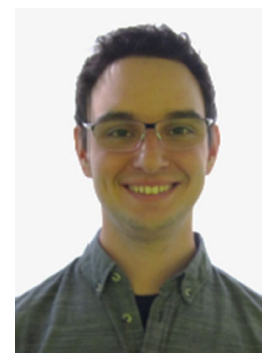

\section{Marcel Knoll}

received the B.Sc. and Dipl.Ing.(M.Sc.) degrees in technical physics from Johannes Kepler University (JKU) Linz, Austria, in 2014 and 2016, respectively. His bachelor thesis dealt with alternative transfer methods for chemical vapor deposited graphene on copper foil and the topic of the master thesis was the production of a fully printed electrochromic display embedded in the organic coating on sheet. He is currently working on his doctoral thesis at the Institute of Microelectronics and Microsensors, JKU Linz. 


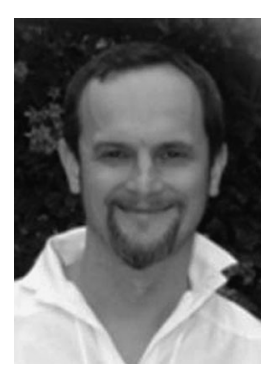

\section{Wolfgang Hilber}

received the Dipl.Ing. (M.SC.) degree in physics and the Ph.D. degree in technical sciences from Johannes Kepler University Linz, Austria, in 1993 and 1997, respectively. After some years of collaboration in research projects at the Carinthian Tech Research (CTR $\mathrm{GmbH})$, Villach, Austria, and at Johannes Kepler University Linz, Austria, in the field of inline process control for semiconductor manufacturing processes, he joined the R\&D Division, E+E Electronics $\mathrm{GmbH}$, Engerwitzdorf, Austria, in 2000. There, he conducted development projects in the field of thin-film sensor technology, mainly for automotive applications, until he finally joined the Institute for Microelectronics and Microsensors, Johannes Kepler University Linz, in 2006, as an Assistant Professor. In 2017, he received the Venia Legendi for sensors and actuators at the Johannes Kepler University Linz. He is currently working in the field of microsensors and microfluidics.

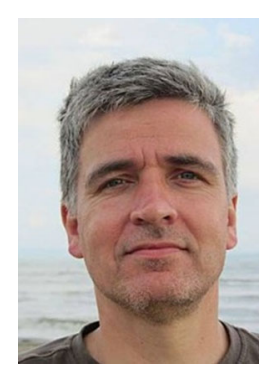

\section{Bernhard Jakoby}

received the Dipl.Ing. (M.Sc.) degree in communication engineering and the Ph.D. degree in electrical engineering from the Vienna University of Technology (VUT), Austria, in 1991 and 1994, respectively. In 2001, he received the Venia Legendi for Theoretical Electrical Engineering from VUT. From 1991 to 1994, he was a Research Assistant at the Institute of General Electrical Engineering and Electronics, VUT. Subsequently, he stayed as an Erwin Schrödinger Fellow at the University of Ghent, Belgium, performing research on the electrodynamics of complex media. From 1996 to 1999, he held the position of a Research Associate and later as an Assistant Professor at the Delft University of Technology, The Netherlands, working in the field of microacoustic sensors. From 1999 to 2001, he was with the Automotive Electronics Division, Robert Bosch GmbH, Germany, where he conducted development projects in the field of automotive liquid sensors. In 2001, he joined the newly formed Industrial Sensor Systems Group, VUT, as an Associate Professor. In 2005, he was appointed as a Full Professor of Microelectronics at Johannes Kepler University Linz, Austria. He is currently working in the fields of liquid sensors and monitoring systems. 